\title{
Virtual Laboratory and Mobile Devices as a Support Tool for the Teaching-Learning Processes of Physics in Pandemic Times
}

\author{
https://doi.org/10.3991/ijes.v9i3.24473 \\ Gustavo Chiodi ${ }^{(凶)}$, Aaron Jose Soutadet, Maria Alejandra Bosio \\ Catholic University of Cordoba, Córdoba, Argentina \\ gchiodi@gmail.com
}

\begin{abstract}
The COVID-19 pandemic forced universities to close their doors creating the largest disruption of education systems in history. It was necessary to find new ways and new alternatives to classical teaching methods. This paper presents the proposal made by the Faculty of Engineering of the Catholic University of Cordoba (UCC) for the continuity of practical laboratory work in the teaching of Physics. To this end, the data obtained from a survey of university students at the end of the academic year 2020 are analyzed. The survey covers first-year students, as well as students from higher education who took Physics I under the classroom modality. It should be noted that the number of students in the Faculty of Engineering of the UCC is very small to obtain conclusive results in a first research, therefore, the authors consider that the project is at an introductory stage that, in the future, will continue to pursue. So far, the results showed that the application of Physics laboratory experiences through simulation can become an excellent tool to facilitate students' understanding of abstract and complex concepts in the face of lack of presence.
\end{abstract}

Keywords_-virtual labs, physics teaching, education in pandemic times

\section{Introduction}

The COVID-19 pandemic forced universities to close their doors creating the largest disruption of education systems in history. It was necessary to find new ways and new alternatives to supply classical teaching methods.

Technological and digital tools, innovation in teaching methods and resources and important investments in communication equipment were needed. Both students and teachers made very large efforts to achieve educational goals.

However, in certain educational aspects, it was very difficult to place some activities in a virtual space. Indeed, some of them, such as laboratory experiences, need a multisensory observation, which is not possible to achieve in virtual environments. The benefits and difficulties of implementing technology-supported education have been 
explored in several case studies in different countries [2] [5] [9]. In this work, a Physics virtual laboratory implementation will be analyzed, and its advantages and disadvantages will be discussed both from teachers' and students' perspectives.

\section{Methods}

This is a qualitative action-research work placed in the classroom that focuses on analyzing the Physics laboratory of the Faculty of Engineering of the Catholic University of Córdoba. Its goal is to reflect upon education and didactic methods and not to prove theories or hypotheses (Ander Egg, 2000).

The study population was made up of physics students from the Engineering degrees of the Catholic University of Córdoba. The information-gathering technique was participant observation and semi-structured interviews. With the collected information, the corresponding tabulation and data analysis was carried out.

Three students' groups were considered:

First group: Students who took the Physics course under the virtual modality.

Second group: Students who took the Physics course under the face-to-face classroom modality using the new laboratory equipment (acquired by the Faculty of Engineering one year ago).

Third group: Students who took the Physics course under the face-to-face modality, but who did not have access to the new laboratory equipment.

The survey was carried out using the Google Forms application including only Newtonian Mechanics questions. This survey was designed in three sections.

In the laboratory practices at the Catholic University of Córdoba, which were historically performed in the usual face-to-face format, the students reproduce the classical Physics experiments.

Physics studies are divided into three main learning areas:

- Physics I: Newtonian Mechanics

- Physics II: Electromagnetism

- Physics III: Thermodynamics and Modern Physics

All engineering students must take these three subjects, in which every learning week is composed of a theoretical class, a problem-solving class, and a laboratory class. Between 2018 and 2019, a large investment in the physics laboratory equipment was done. In this context, new experiences and new laboratory procedures were designed and implemented during 2019 [1].

Since March 2020, the restrictions imposed by the Covid-19 pandemic forced to move all the teaching activities to the virtual modality. The laboratory classes were affected by this since the role of the students in the experimental environment is very different from the one played in the theoretical and practical classes. Laboratory experiences require active student participation, including environment interaction and interpretation, teamwork, development of creativity, materials and methods selection to achieve goals. It requires as well the physical interpretation of the experiment, building empirical models, sharing ideas, learning from mistakes and thinking about immediate 
consequences. It is also necessary to be careful with danger, following safety rules, finding alternative procedures when the ordinary ones cannot be carried out, optimizing resource use and so on. All of these elements and many more make laboratory practices irreplaceable. However, it is possible to create a virtual environment, that, although lacking many of the virtues of a real laboratory, enhances other characteristics that can benefit the students in their learning process.

These are virtual spaces where students, instead of observing a real physical phenomenon and translating it into a theoretical model, do the inverse operation, that is, analyzing a theoretical model to interpret the real physical phenomenon. These theoretical models are not presented as equations, but as an environment that simulates the real world on virtual spaces. Also, other alternatives can be implemented, such as, for example, Remote Laboratories, which require a remote connection with some measurement equipment, and Deferred Laboratories, which perform data collection through a previously filmed experiment [2].

\subsection{Virtual labs}

The Physics Laboratory of the Catholic University of Córdoba chose to utilize simulations as a virtual laboratory tool in Physics. Some of the proposed virtual labs and their fundamental characteristics are discussed below:

Case one: capacitor lab. It is a Physics simulation tool to explore how a capacitor works (Figure 1). It is possible to change the size of the plates, add a dielectric, change the voltage and see charges built up on the plates. It shows the electric field in the capacitor and it is possible to measure voltage and electric field.

Phet Interactive Simulation: https://phet.colorado.edu/es/simulation/legacy/ capacitor-labUnits

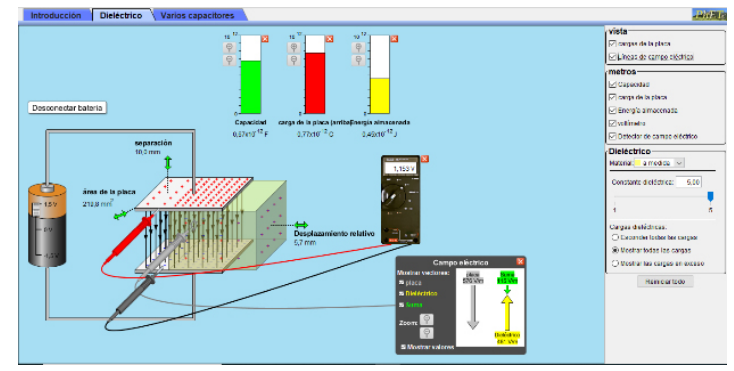

Fig. 1. Capacitor lab

Case two: circuit construction kit (AC+DC), virtual lab. This physic simulation permits to build circuits with capacitors, inductors, resistors and AC or DC voltage sources, and inspect them using lab instruments such as voltmeters and ammeters (Figure 2).

Phet Interactive Simulation: https://phet.colorado.edu/es/simulation/circuitconstruction-kit-dc-virtual-lab 


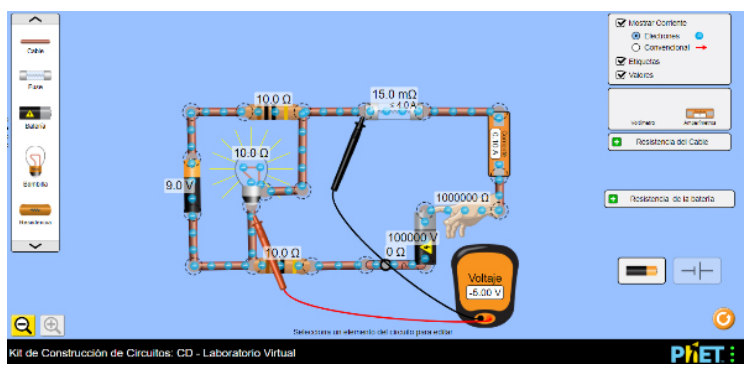

Fig. 2. Circuit construction kit (AC+DC), virtual lab

Case three: multimeter. It simulates an electrical measuring instrument with the functions of an ammeter (current measurement), a voltmeter (voltage measurement), and an ohmmeter (resistance measurement) (Figure 3).

eduMedia: https://www.edumedia-sciences.com/es/media/552-multimetro

Case four: vernier caliper. Virtual Vernier caliper is a caliper reading, interpretation and practice simulator with a scale resolution of $0.05 \mathrm{~mm}$ (Figure 4).

Prof. Eduardo J. Stefanelli: https://www.stefanelli.eng.br/es/calibre-virtualsimulador-milimetro-02/

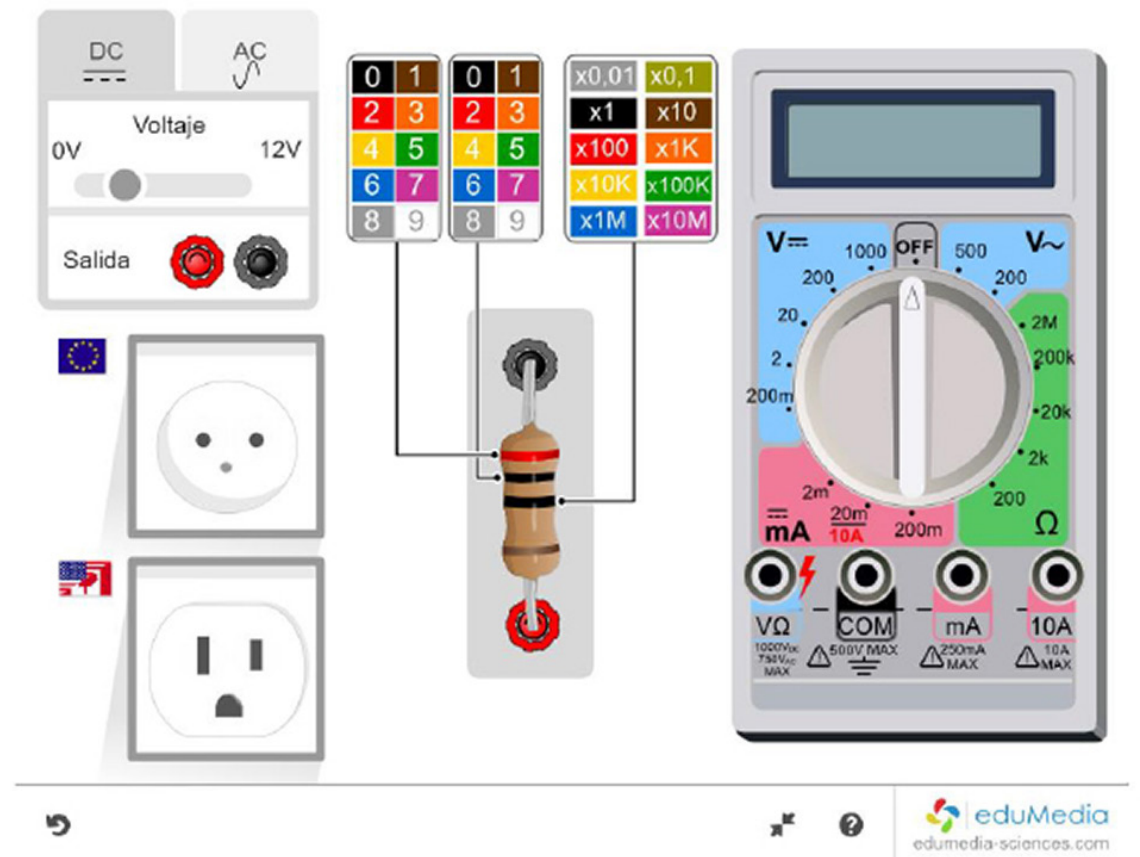

Fig. 3. Multimeter 


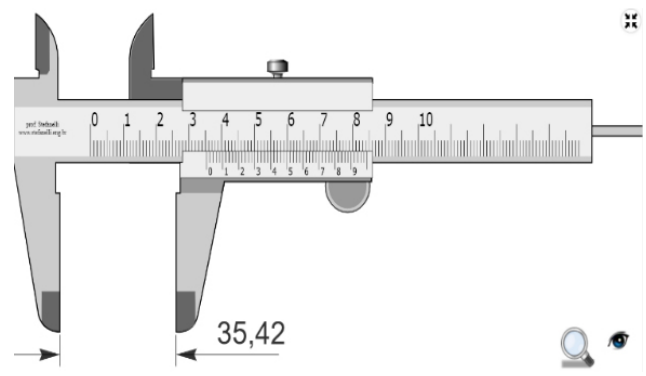

Fig. 4. Vernier caliper

Case five: masses and springs. This physic simulation permits to hang masses from springs and adjust the spring constant and damping, to change the force of gravity value and slow downtime (Figure 5). The forces and energy in the system can be observed in real-time and it is possible to measure the period using the stopwatch.

Phet Interactive Simulation: https://phet.colorado.edu/es/simulation/massesand-springs

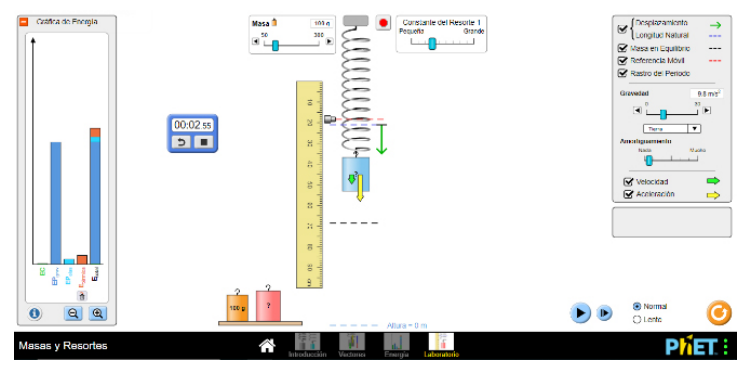

Fig. 5. Masses and springs

Case six: projectile motion. It allows students to learn about projectile motion by firing various objects (Figure 6). It is possible to set parameters such as angle, initial speed, and mass, to explore vector representations, and to add air resistance to investigate the factors that influence the drag.

Phet Interactive Simulation: https://phet.colorado.edu/es/simulation/projectilemotion

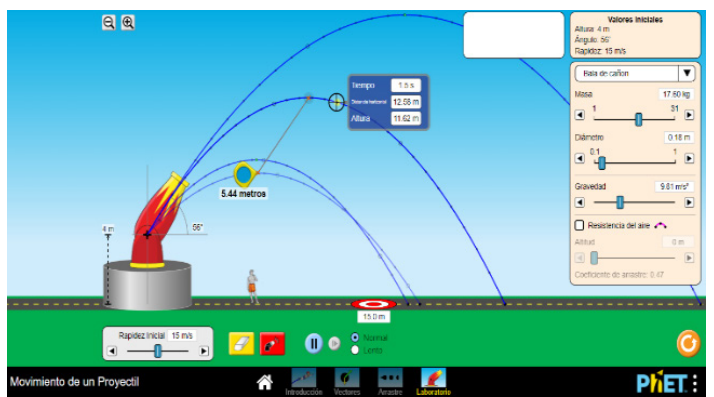

Fig. 6. Projectile motion 
Case seven: energy skate park. It permits students to learn about energy conservation with a skater gal. It is possible to explore different tracks and view the kinetic energy, potential energy and friction as she moves, to build tracks, ramps and jumps for the skater (Figure 7).

Phet Interactive Simulation: https://phet.colorado.edu/es/simulation/energy-skatepark-basics

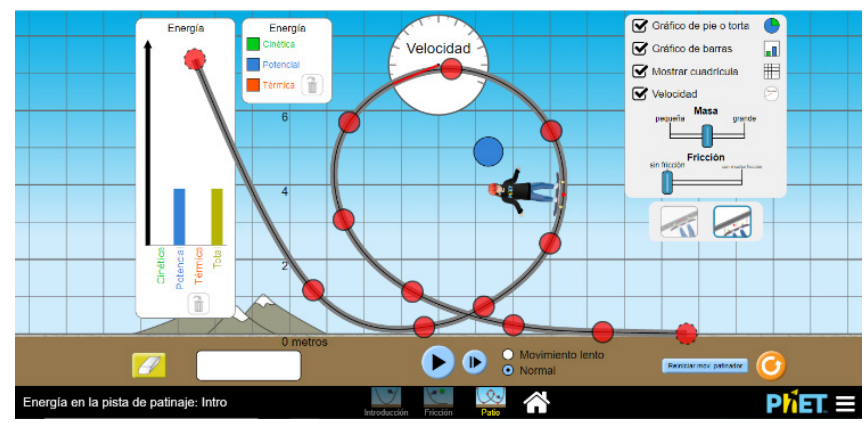

Fig. 7. Energy skate park

Case eight: pendulum lab. It enables playing with one or two pendulums and discovering how the period of a simple pendulum depends on the length of the string, the mass of the pendulum bob, the strength of gravity, and the amplitude of the swing. It is possible to observe the energy in the system in real-time, and vary the amount of friction and measure the period using the stopwatch or period timer (Figure 8).

Phet Interactive Simulation: https://phet.colorado.edu/es/simulation/pendulum-lab

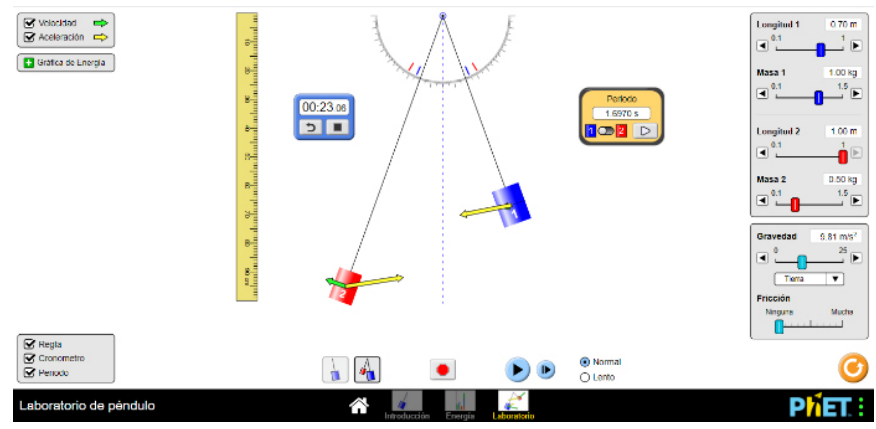

Fig. 8. Pendulum lab

Case nine: photoelectric effect. It allows students to see how light knocks electrons off a metal target and to recreate the experiment that spawned the field of quantum mechanics (Figure 9).

Phet Interactive Simulation https://phet.colorado.edu/es/simulation/legacy/ photoelectric 


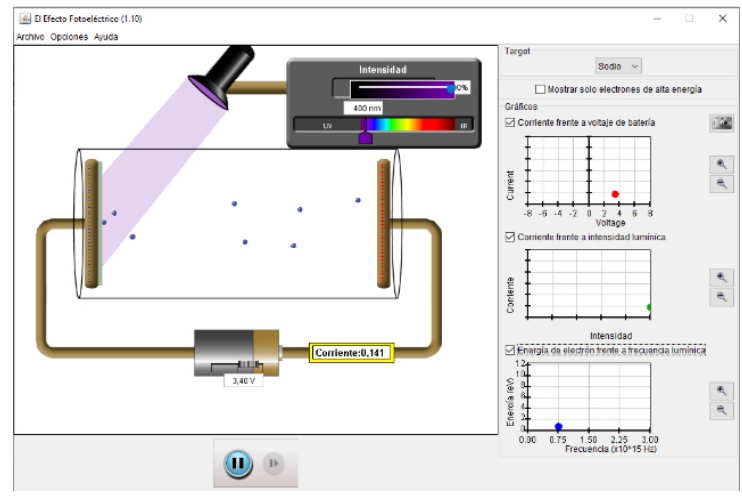

Fig. 9. Photoelectric effect

Case ten: wave on a string. It allows students to see how light knocks electrons off a metal target and to recreate the experiment that spawned the field of quantum mechanics (Figure 10).

Wave on a String: https://phet.colorado.edu/es/simulation/wave-on-a-string

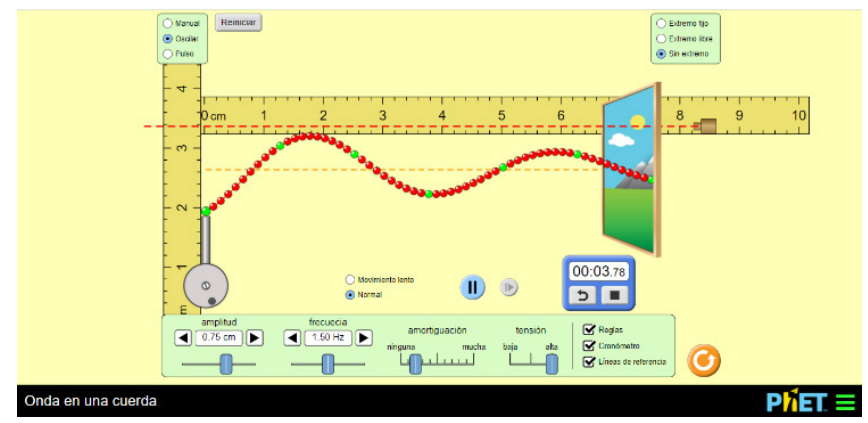

Fig. 10. Wave on a string

\subsection{Advantages of virtual labs concerning face-to-face practices}

Virtual labs have advantages and disadvantages compared to traditional laboratories [3]. These assessments are evaluated from the student's point of view [4] [5] and the teacher's point of view.

Some advantages of virtual labs are listed below:

- They allow students to try out different scenarios. As shown in case one, with virtual labs it is possible to observe what is happening when the area of the plates is modified, when a linear insulator is introduced, when the distance between the plates is changed, or when a source is disconnected or connected. It also enables to observe 
what happens with the electric field and how the charge density varies in the armor or the insulator. All these scenarios cannot be achieved in the real labs, and usually cannot be fully exposed either in the theoretical or in the practical classes by the reduced time imposed by the school cycle.

- Less time is needed. The time is used to the situation modeling and not to assembly or disassembly of real equipment. It also does not require set-up or testing, since the results do not depend on the environmental conditions or the user's ability. No maintenance is needed only the optional applications updates.

- It can be used anytime and anywhere.

- The lab experiences can be repeated many times as desired without material costs.

- Virtual labs are a good alternative for some dangerous and/or very expensive experiences.

\subsection{Disadvantages of virtual labs converning face-to-face practices}

- Even though the virtual labs have all the advantages said above, there are some learning instances that only the face to face labs can achieve. These limitations, added to the disadvantages listed below, make virtual labs a complementary tool in the teaching of Physics [6]:

- Virtual labs do not promote teamwork; each student can work on his own. In real laboratories, on the other hand, students must share the elements and each one must assume a specific role.

- Many material systems qualities can be observed using the touch and/or the smell sense, such as the temperature of a body, the smell of a burnt resistor or capacitor, and so on. Simulators cannot recreate these experiences.

- As students do not use real tools it is not possible to achieve laboratory equipment use skills [7].

- Awareness of danger is lost. In simulators nothing can be damaged, therefore, the safety guidelines are not considered. Likewise, if there was the possibility that the student did a real practice in his/her home, he/she would not have trained supervision which increases accident probabilities.

- The inherent learning of the measurement and data collection process is lost. Although there are a lot of simulators that permit training in the measurement instruments uses, they cannot show the randomness of the samples. If many students measure an object in a simulated way, all of them will obtain the same result, regardless of environmental conditions, the state of the instrument, or the operator skills.

\subsection{Surveys carried out and level of satisfaction}

The above-discussed labs were implemented in the three Physics courses of the Faculty of Engineering. To obtain a compared vision with the face to face course about student's opinion and learning level achieved, a survey was implemented. Three student's groups were considered: 
First group: Students who took Physics course under the virtual modality.

Second group: Students who took Physics course under the face to face classroom modality, using the new laboratory equipment.

Third group: Students who took Physics course under the face-to-face modality, but did not have access to the new laboratory equipment.

The survey was carried out using Google Forms application including only Newtonian Mechanics questions. This survey was designed in three sections.

Section 1: Training in Experimental Physics in high school and the current situation. In this section, both open and closed questions were defined to determine whether the student carried out laboratory practices in the Secondary School; which career they have chosen, and if they took Physics I more than once. These questions' answers allowed us to classify the students into one of the three groups mentioned above.

Section 2: How the Physics I subject was completed. In this section, open and closed questions were asked to find out the student's opinions about the laboratory practices carried out in each group.

Section 3: Basic laboratory concepts evaluation. In this section, open and closed questions were asked to evaluate the students' learning about laboratory topics, such as determining the reading of a gauge, giving the result of a hydrostatic experiment, determining the gravity of someplace by measuring a pendulum period, among others.

\section{Results}

A total of 115 students were surveyed. Some of them had taken the subject in the face-to-face modality (distinguishing whether or not they used the new lab equipment), and others had taken the subject in the virtual course.

The survey results are summarized below:

1. $10,4 \%$ of the surveyed students did not take Physics in secondary school. Of the remaining $89.6 \%, 46.6 \%$ never had a laboratory experience in high school (Figure 11).

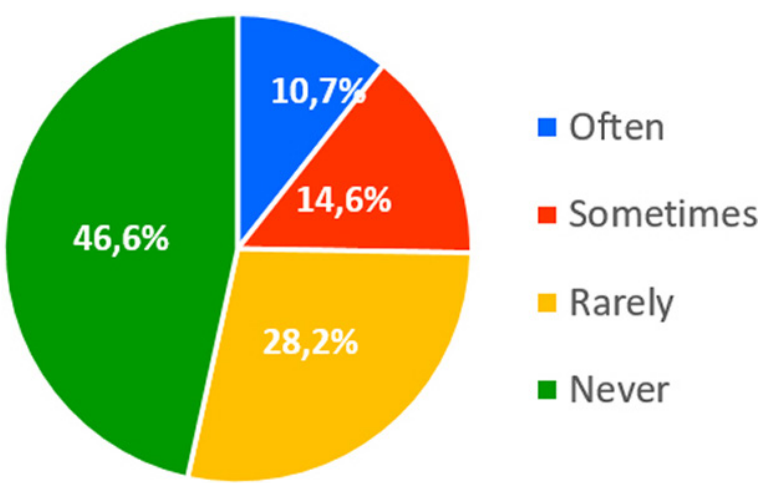

Fig. 11. Percentage of students who have had laboratory practice in secondary school 
2. $8,7 \%$ of the surveyed students took the Physic I course more than once. $89,9 \%$ of the remaining $91,3 \%$ took Physics I in virtual modality.

3. $69 \%$ of the surveyed students that took Physic I in virtual modality thinks that virtual labs helped them to understand the theoretical topics. Only $2.3 \%$ of the surveyed students think that the virtual labs did not influence the understanding of the topics (Figuer 12).

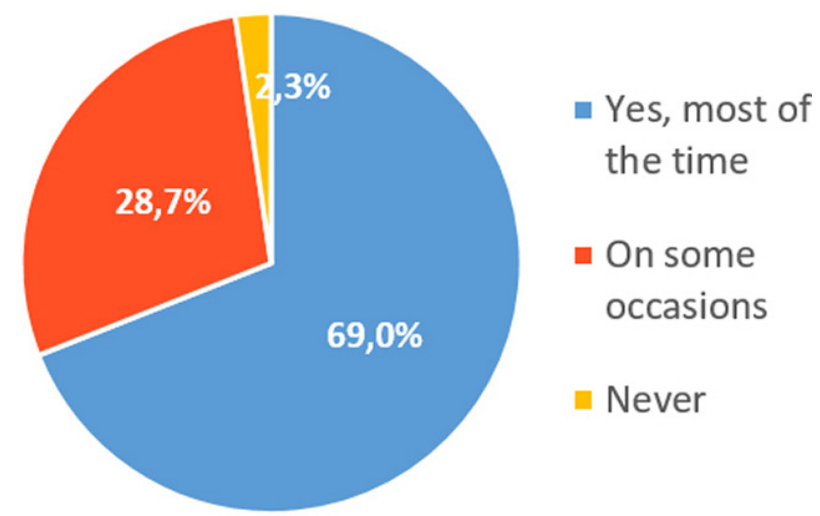

Fig. 12. Percentage of students who report that virtual workshops had a positive impact on the understanding of concepts

4. $60 \%$ of the surveyed students that took physic I in the face to face modality, fully agree that the new equipment enables a better topics understanding (Figure 13).

In section three of the survey, 10 questions were asked, to evaluate laboratory topics. The correct answers percentage was calculated for each question and group (Figure 14).

Section two results are presented in Figure 15 and Figure 16. As it can be observed, there is a good satisfaction degree with both modalities, but slightly higher for the faceto-face course.

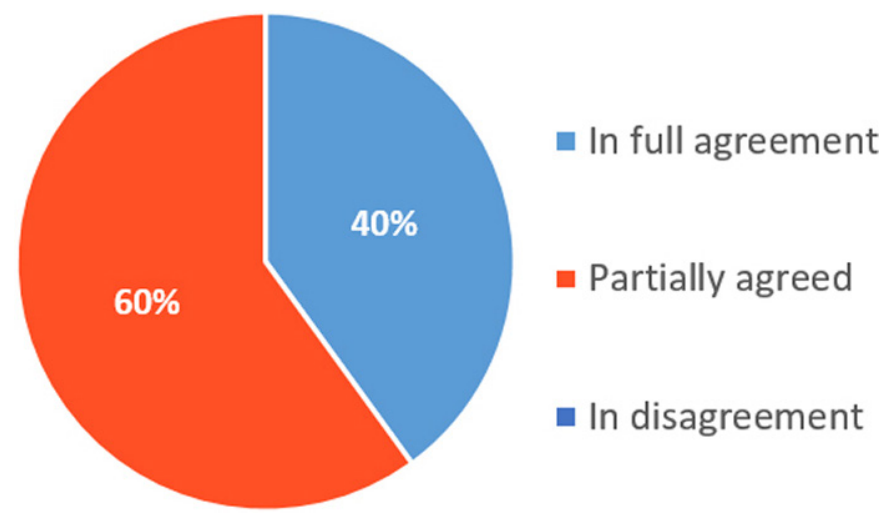

Fig. 13. Percentage of students who report that the new laboratory equipment acquired allows them to have a better understanding of the subjects addressed in the subject 


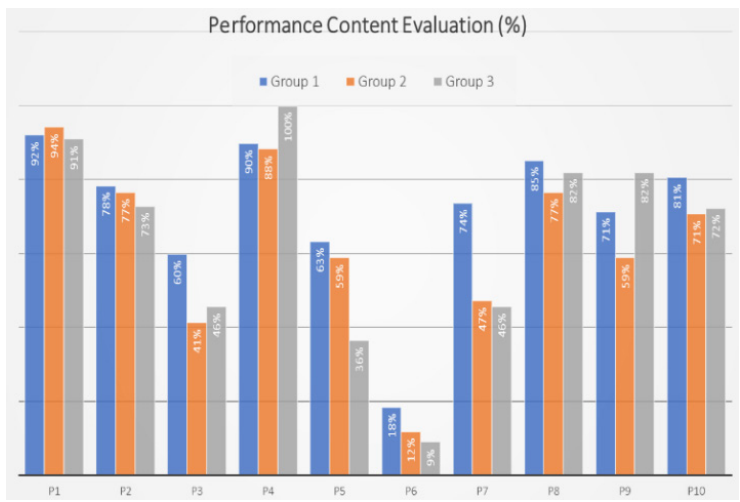

Fig. 14. Students' performance in the evaluation of laboratory contents. Group 1: students who studied physics i under the virtual modality. Group 2: students who studied physics I taking advantage of the new laboratory equipment acquired. Group 3: students who studied physics I under the classroom modality, but who did not have the new equipment

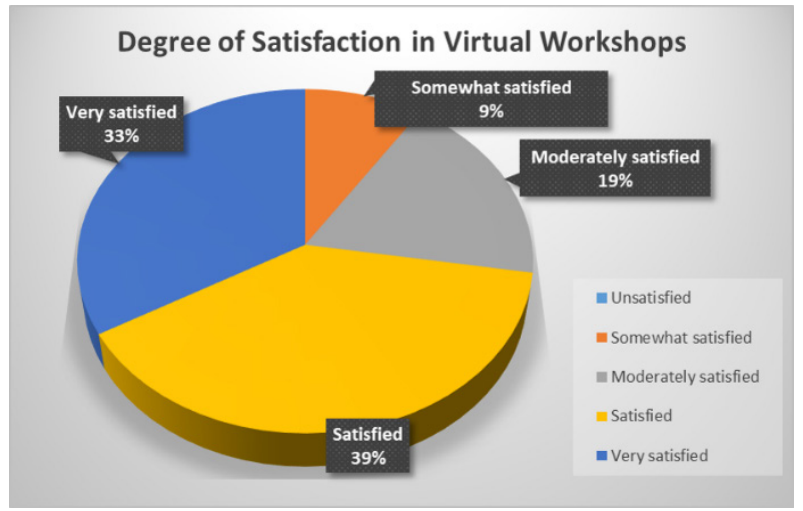

Fig. 15. Level of satisfaction with virtual workshops

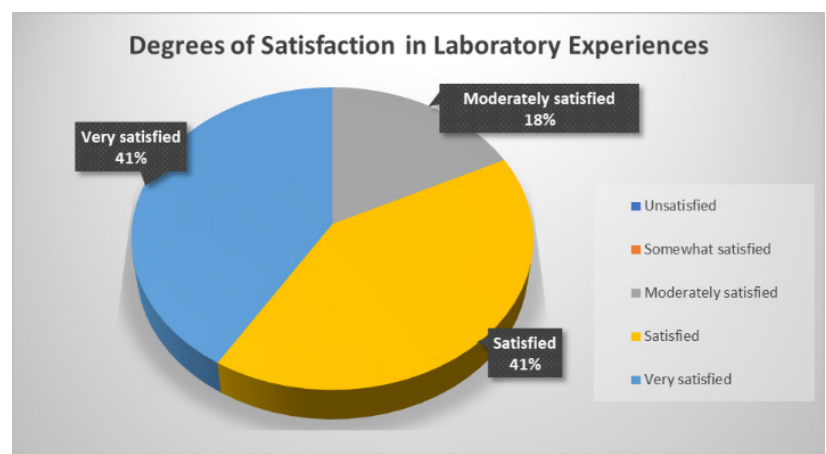

Fig. 16. Level of satisfaction in laboratory experiences with the new equipment purchased 


\section{Conclusions}

Both, virtual and face-to-face laboratories have a positive influence on the students' understanding of the physic topics [8]. The students' performance in the laboratory content assessments was slightly higher for the virtual group than for the face-to-face group. This could be a consequence of the fact that the students of the virtual course were trained from a more theoretical and analytical conception. However, this cannot be interpreted as a teaching advance. If the students of the virtual course should be evaluated in real laboratories, probably they would have lower performance than the students of the face-to-face course.

The students' assessment of the virtual labs their advantages and disadvantages agree with the teacher's assessment. These labs were well received by the students. since helped them to understand, with very little cost of time, those topics that were not fully exposed in the theoretical or practical classes.

Virtual labs have the advantage of being able to recreate more scenarios than those commonly analyzed in theoretical and practical classes. Also, they are an excellent complement to verify the answer in problem-solving. But, on the other hand, a small student group who, although appreciating the teaching adaptation methods in pandemic times, would have liked to have experience working in a real laboratory.

However, the potential of virtual labs as a teaching resource for the three modalities (theoretical, practical and laboratories) should not be underestimated, since they create a clear vision in the student's mind, ordering their ideas, and facilitating the teaching work to express the theoretical contents.

Virtual labs cannot replace laboratory practices, but they can be considered as an excellent tool to use in the face-to-face modality, and as an optimal contingency plan in the virtual modality.

\section{$5 \quad$ References}

[1] A. J. Soutadet, Fisica I. Guía de trabajos practicos de laboratorio, Córdoba: EDUCC-Editorial de la Universidad Católica de Córdoba, 2019.

[2] Abd.Rahman, Norliza Binti; Mohd Ali, Jarinah Binti; Baharom, Mohd Afiq Bin. Preliminary Development of MyAras: Level 1 Mobile Virtual Lab. International Journal of Emerging Technologies in Learning, [S.1.], v. 14, n. 24, pp. 131-139, dec. 2019. ISSN 1863-0383. Available at: https://online-journals.org/index.php/i-jet/article/view/12125. Date accessed: 24 Apr. 2021. doi: https://doi.org/10.3991/ijet.v14i24.12125

[3] C. Infante Jiménez, «Propuesta pedagógica para el uso de laboratorios virtuales como actividad complementaria en las asignaturas teórico-prácticas,» Revista Mexicana de Investigacion Educativa, vol. 19, no 62, pp. 917-937, 2014.

[4] D. Rodriguez Llerena y J. Llovera González, «Estudio comparativo de las potencialidades didacticas de las simulaciones virtuales y de los experimentos reales en la enseñanza de la Física General para estudiantes universitarios de ciencias tecnicas,» Latin-American Journal of Physics Education, vol. 4, nº 1, pp. 181-187, 2010. 
[5] Díaz, Jairo Eduardo Márquez. Virtual World as a Complement to Hybrid and Mobile Learning. International Journal of Emerging Technologies in Learning (iJET), [S.1.], v. 15, n. 22, pp. 267-274, nov. 2020. ISSN 1863-0383. Available at: https://online-journals.org/index. php/i-jet/article/view/14393. Date accessed: 24 Apr. 2021. doi: https://oi.org/10.3991/ijet. v15i22.14393

[6] G. Amaya Franky, «Laboratorios reales versus laboratorios virtuales, en la enseñanza de la Física,» El hombre y la máquina, nº 33, pp. 82-95, 2009.

[7] J. Monge Nájera y V. H. Méndez Estrada, «Ventajas y desventajas de usar laboratorios virtuales en educacion a distancia; la opinion del estudiantado en un proyecto de seis años de duración,» Educacion, vol. 31, n 1, pp. 91-108, 2007. https://doi.org/10.15517/revedu.v31i1.1255

[8] L. Rivera, M. Román, J. P. Moncayo y D. Ordóñez Cabrera, «Laboratorio virtual de Fisica,» Revista de Informatica Educativa y Medios Audiovisuales, vol. 6, nº 12, pp. 8-12, 2009.

[9] Tugun, Vasfi et al. The Opinions of Technology Supported Education of University Students. International Journal of Emerging Technologies in Learning (iJET), [S.1.], v. 15, n. 23, pp. 4-14, dec. 2020. ISSN 1863-0383. Available at: https://online-journals.org/index. php/i-jet/article/view/18779. Date accessed: 24 Apr. 2021. https://oi.org/10.3991/ijet. $\underline{\mathrm{v} 15 \mathrm{i} 23.18779}$

\section{Authors}

Gustavo Chiodi, Faculty of Engineering, Catholic University of Cordoba. E-mail: gchiodi@gmail.com.

Aaron Jose Soutadet, Faculty of Engineering, Catholic University of Cordoba. E-mail: aaron.soutadet@gmail.com.

Maria Alejandra Bosio, Faculty of Engineering, Catholic University of Cordoba. E-mail: malejandra.bosio@gmail.com.

Article submitted 2021-06-02. Resubmitted 2021-07-12. Final acceptance 2021-07-15. Final version published as submitted by the authors. 